\title{
Spatial pattern of natal signatures in the otoliths of juvenile kelp rockfish along the Californian coast
}

\author{
Julie D. Standish ${ }^{1, *}$, J. Wilson White ${ }^{2}$, Robert R. Warner ${ }^{1}$ \\ ${ }^{1}$ Department of Ecology, Evolution, and Marine Biology, University of California, Santa Barbara, California 93106, USA \\ ${ }^{2}$ Department of Wildlife, Fish, and Conservation Biology, University of California, Davis, One Shields Ave, Davis, \\ California 95616, USA
}

\begin{abstract}
The natal origin of a post-dispersal marine fish may be determined by examining the trace elemental signatures present in the core (i.e. the pre-dispersal region) of the otolith. We found distinct spatial differences in the natal elemental signatures in the core region of the otoliths of postdispersal juvenile kelp rockfish Sebastes atrovirens collected along the coast of California, USA. Laser ablation inductively coupled plasma mass spectrometry of individual otolith cores revealed detectable levels of $\mathrm{Mn}, \mathrm{Mg}, \mathrm{Ba}$, and Sr. Using a Bayesian classification model, 2 unique elemental signature types were identified in both 2001 and 2002, and the signatures were chemically similar across years. In both years, locations received a mixture of natal types ('A' and 'B'), indicating the contribution of at least 2 chemically distinct sources to recruitment. The spatial pattern of the natal types varied among sites for both years. In 2001, Type A was nearly absent from the northernmost location, suggesting a southern origin and a limitation in the dispersal and contribution of this chemically identified natal type. In 2002, most locations had a mix of Types A and B, but Type A was most abundant in the south and least abundant in the central part of the spatial domain. However, it was not possible to specify the full extent of dispersal of either natal type. We demonstrated use of elemental signatures in the otolith core of post-dispersal individuals to evaluate larval dispersal patterns which may document the extent to which kelp rockfish populations along the California coast receive recruits from different chemically distinct sources.
\end{abstract}

KEY WORDS: Larval dispersal · Otolith chemistry - Otolith natal signature · Mass spectrometry · Sebastes atrovirens

Resale or republication not permitted without written consent of the publisher

\section{INTRODUCTION}

Many marine populations are linked by the dispersal of planktonic larvae. The pathways traveled by larvae and the spatial scales at which populations are connected by larval dispersal are important for understanding population dynamics and community structure (Caley et al. 1996, Warner \& Cowen 2002) and are essential for the effective placement of management boundaries and design of marine protected areas (Carr \& Reed 1993, Botsford et al. 2003, 2009). However, larval dispersal remains poorly understood, and disper- sal distances have been estimated for only a small group of marine species (Shanks 2009).

Due to the small size and potential for long distance travel of larvae of most benthic marine organisms, studies of larval dispersal have proven to be very challenging. Most genetic techniques offer only indirect estimates of dispersal distance and long-term dispersal patterns (Kinlan \& Gaines 2003). In addition, artificial tagging techniques are usually not feasible because of the high larval mortality rates during dispersal that make recovery of tagged larvae exceedingly unlikely (but see Jones et al. 1999 and Almany et al. 2007). In 
contrast, recent studies using natural environmentallyinduced markers in the hard parts of fishes or invertebrates have offered some promise in tracking the environmental history of individuals and in identifying movement patterns of larvae among populations (DiBacco \& Levin 2000, Thorrold et al. 2001, Gillanders 2002, Becker et al. 2007). Here, we used the elemental concentrations in otoliths to identify dominant larval dispersal patterns in fishes that live along open coastlines.

Otoliths, structures in the inner ear of fishes used for balance, orientation, and hearing, are formed during the embryonic stage and grow concentrically by the daily deposition of calcium carbonate crystals into a proteinaceous matrix. At the time of deposition, trace elements from the surrounding water are incorporated into the calcium carbonate matrix of the otolith, and a central nucleus forms the core of the otolith. The otolith elemental concentrations appear to reflect the physical and chemical properties of the water mass in which they were formed, although not necessarily in a straightforward manner (Bath et al. 2000, Elsdon \& Gillanders 2003, de Vries et al. 2005). In addition, because otolith material once deposited is not reworked, the otolith material forms a permanent record of past environmental conditions experienced by the individual (Campana 1999). Otolith elemental composition has been used to determine adult stock structure (Campana et al. 1994, Fowler et al. 2005) and to reconstruct migration patterns and environmental conditions experienced by fishes (Swearer et al. 1999, Secor et al. 2001, Thorrold et al. 2001, Hamilton et al. 2008).

Emerging work analyzing the otoliths from larval fish sampled prior to dispersal have documented unique elemental signatures among different natal sites (Warner et al. 2005, Ruttenberg \& Warner 2006), demonstrating that otolith elemental signatures have the potential to discriminate the geographic origin of post-dispersal fish, particularly when an atlas of natal elemental signatures is obtained (Ruttenberg et al. 2008). For open coast species, the complete sampling of larval otoliths from all potential source locations is not feasible, and restricted spatial sampling of larval otoliths can only offer limited information. For instance, the characterization of natal elemental signatures within a restricted geographic area can only provide information on whether older individuals (i.e. post-dispersal recruits or adults) have come from outside the sampled area (Standish et al. 2008).

An alternative to the collection of pre-dispersal larval otoliths is the comparison of elemental signatures at the otolith core, formed during the earliest life stage, of post-dispersal juvenile fish collected across a broad geographic region. The spatial pattern produced from this analysis can provide information about dispersal scales and the degree to which different populations receive recruits from different sources (Ashford et al. 2006, Fontes et al. 2009). For example, Miller \& Shanks (2004) sampled the early-larval to late-larval/early juvenile portions of otoliths from juvenile black rockfish Sebastes melanops and found unique otolith elemental signatures throughout ontogeny in samples collected 120 to $420 \mathrm{~km}$ apart along the OregonWashington (USA) coast, suggesting separate origins and dispersal trajectories during their early larval and pelagic juvenile period over this geographic scale.

We analyzed natal elemental signatures in the otolith cores of kelp rockfish Sebastes atrovirens recruits to examine larval dispersal patterns along the open coast of California. We assayed otoliths from recruits sampled from locations along the coast in 2001 and 2002. Using a Bayesian classification model, the core elemental concentrations were grouped to classify distinct natal elemental signature types. Natal signature types are assumed to represent chemically unique elemental signatures from source population(s), and we analyzed the spatial pattern of the occurrence of natal signature types among the collection locations for both years. Our efforts concentrated on differences among locations, especially the restriction of unique natal elemental types, which may provide information regarding potential barriers to larval dispersal.

\section{MATERIALS AND METHODS}

Species characteristics and sample collection. Sebastes atrovirens is a common inhabitant of nearshore subtidal kelp communities and ranges from northern California, USA, to central Baja California, Mexico (Love et al. 2002). Sebastes females are primitively viviparous, internally brooding young for a period of 1 to 2 mo before release into the pelagic phase (Wourms 1991). During the period in which the embryo is still within the mother, the natal portion of the otolith is formed. Sebastes larvae are born at an advanced stage of development in which organogenesis is essentially complete; hence they are active, feeding larvae (Wourms 1991). Female S. atrovirens generally release larvae from February through June; after a 2 to 3 mo pelagic stage, larvae settle to shallow coastal waters and giant kelp Macrocystis pyrifera canopies during the summer and early fall (Love et al. 2002). Once settled, juveniles remain closely associated with kelp, and adults are relatively sedentary, generally moving only a few meters within their home reefs (Love et al. 2002).

Post-settlement Sebastes atrovirens recruits were collected from sites spanning the central California 


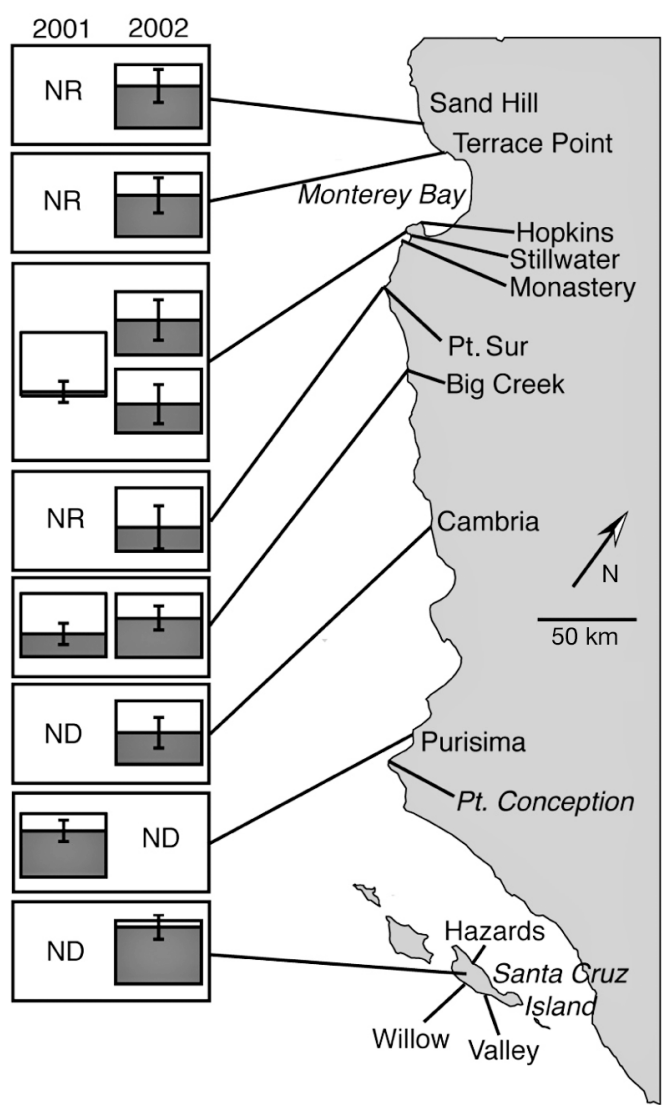

Fig. 1. Sebastes atrovirens. Collection sites within south-central California, USA, and the proportion of recruits collected at each location in each year that were of natal signature Type A (dark gray) or Type B (white). NR: no recruitment of $S$. atrovirens in that location in that year; ND: no data. Error bars: SD of the proportional assignment, calculated from randomly generated datasets in which the Markov chain-Monte Carlo method identified at least 2 clusters $(n=5, n=6$, for 2001 and 2002, respectively) coast, from north of Monterey Bay to Santa Cruz Island off the coast of Santa Barbara (Fig. 1). This study region lies well within the geographic range of $S$. atrovirens, and genetic evidence suggests that the population of a congener, $S$. mystinus, is well-mixed in this region over evolutionary time scales (Burford \& Larson 2007). However, this region does span Pt. Conception, a biogeographic break for many species and a potential dispersal barrier for pelagic larvae due to the separation of the coastal upwelling jet from the coastline at the point (Harms \& Winant 1998, Horn et al. 2006, Broitman et al. 2008). Other Sebastes species exhibit restricted larval dispersal within this coastal region (e.g. Buonaccorsi et al. 2004, Hyde \& Vetter 2009), so we suspected that $S$. atrovirens settling at different sites in a given year may have originated from distinct source locations.

Recruits were collected from near-surface kelp canopies using nets and near-surface artificial collectors (for collector details see Ammann 2004). In 2001, recruits were collected by net between 24 and 27 August at 3 sites (Hopkins, Stillwater, and Monastery Reef) near the southern end of Monterey Bay (hereafter referred to as Monterey) and Big Creek (Fig. 1). Recruits collected at Purisima were sampled on 24 July 2001 from artificial collectors (Fig. 1). In 2002, recruits were collected by net from 17 to 26 September at mainland locations along the California coast (Fig. 1). Samples from Santa Cruz Island were collected every $2 \mathrm{wk}$ between July and October 2002 from artificial collectors (Fig. 1, Table 1). All samples were frozen immediately after capture.

Sample preparation. Fish were thawed and measured to the nearest $0.5 \mathrm{~mm}$ (standard length, SL), and sagittal otoliths were removed. Otoliths were cleaned

Table 1. Sebastes atrovirens. Sites and dates of collection, total ages, and birthdates for kelp rockfish recruits sampled in 2001 and 2002. Sample sizes for chemical $\left(n_{c}\right)$ and birthdate $\left(n_{b}\right)$ analyses for each location are shown. Dates are given as $\mathrm{mm} / \mathrm{dd} / \mathrm{yy}$

\begin{tabular}{|c|c|c|c|c|c|c|c|}
\hline \multirow[t]{2}{*}{ Site } & \multirow{2}{*}{$\mathrm{n}_{\mathrm{c}}$} & \multirow{2}{*}{$\mathrm{n}_{\mathrm{b}}$} & \multicolumn{2}{|c|}{$\longrightarrow$ Age $(\mathrm{d}) \longrightarrow$} & \multirow[t]{2}{*}{ Collection date } & \multicolumn{2}{|c|}{ Birthdate -} \\
\hline & & & Mean \pm SE & Range & & Mean & Range \\
\hline \multicolumn{8}{|l|}{2001} \\
\hline Monterey $^{\mathrm{a}}$ & 15 & 13 & $91.2 \pm 1.5$ & $80-100$ & 8/24-26/01 & $5 / 25 / 01$ & $5 / 17 / 01-6 / 07 / 01$ \\
\hline Big Creek & 11 & 9 & $96.3 \pm 3.9$ & $74-112$ & 8/27/01 & $5 / 23 / 01$ & $5 / 07 / 01-6 / 14 / 01$ \\
\hline Purisima & 11 & 11 & $61.7 \pm 2.1$ & $54-75$ & $7 / 24 / 01$ & $5 / 23 / 01$ & $5 / 10 / 01-5 / 31 / 01$ \\
\hline \multicolumn{8}{|l|}{2002} \\
\hline Sandhill & 21 & 17 & $95.0 \pm 1.6$ & $86-117$ & 9/17/02 & $6 / 14 / 02$ & $5 / 23 / 02-6 / 23 / 02$ \\
\hline Terrace & 20 & 19 & $97.0 \pm 2.0$ & $79-116$ & 9/17/02 & 6/12/02 & $5 / 24 / 02-6 / 30 / 02$ \\
\hline Hopkins & 18 & 16 & $97.6 \pm 2.3$ & $77-118$ & 9/19/02 & 6/13/02 & $5 / 24 / 02-7 / 04 / 02$ \\
\hline Stillwater & 22 & 20 & $98.6 \pm 1.6$ & $86-112$ & 9/19/02 & $6 / 12 / 02$ & $5 / 30 / 02-6 / 25 / 02$ \\
\hline Point Sur & 21 & 19 & $100.7 \pm 3.6$ & $73-127$ & $9 / 26 / 02$ & 6/19/02 & $5 / 22 / 02-7 / 15 / 02$ \\
\hline Big Creek & 21 & 18 & $103.9 \pm 2.5$ & $82-124$ & $9 / 26 / 02$ & $6 / 14 / 02$ & $5 / 25 / 02-7 / 06 / 02$ \\
\hline Cambria & 10 & 10 & $113.7 \pm 4.1$ & $92-130$ & $10 / 5 / 02$ & $6 / 13 / 02$ & $5 / 28 / 02-7 / 05 / 02$ \\
\hline Santa Cruz & 40 & 34 & $62.7 \pm 0.9$ & $49-72$ & $7 / 02-8 / 01 / 02$ & $5 / 12 / 02$ & $4 / 23 / 02-5 / 31 / 02$ \\
\hline
\end{tabular}


of adhering tissue, rinsed in distilled water, air-dried, and stored in individual wells in multi-well polycarbonate tissue culturing trays. One otolith from each individual was mounted on an acrylic slide using lowviscosity epoxy resin (Epo-Thin, Buehler). To expose the growth rings and natal core, each otolith was polished to within 10 to $20 \mu \mathrm{m}$ of the core using a lapping wheel and 3 and $9 \mu \mathrm{m} 3 \mathrm{M}$ diamond polishing film.

Individual ages of recruits were determined using otolith microstructure analysis. Several studies have validated daily otolith-increment deposition in juvenile Sebastes spp. (Yoklavich \& Boehlert 1987, Plaza et al. 2001). Polished otoliths were examined at $400 \times$ magnification with an Olympus BX50 compound microscope to visualize and count individual otolith increments. Ralston et al. (1996) confirmed a dark ring at the edge of the nuclear radius in larval otoliths of shortbelly rockfish Sebastes jordani as an extrusion mark. An extrusion mark has also been identified on the otoliths of $S$. atrovirens recruits (Standish et al. 2008), and we used this information to count daily increments from the extrusion mark to the otolith edge of each recruit. Birthdate was determined by back-calculating age from the date of capture.

To remove surface contaminants and reduce organic material prior to chemical analysis, otoliths were rinsed in ultra pure water ( $\mathrm{N}$-pure, resistivity >18.1 M $\Omega$ ), soaked in semiconductor grade $15 \% \mathrm{H}_{2} \mathrm{O}_{2}$ buffered with Suprapur $0.05 \mathrm{~N} \mathrm{NaOH}$ in acid-leached plastic trays for $1 \mathrm{~h}$, rinsed again with $\mathrm{N}$-pure, soaked, and sonicated 3 times in N-pure for $5 \mathrm{~min}$ and rinsed in a final N-pure wash and air-dried in a HEPA-filtered Class 100 laminar flow bench.

Analytical methods. Recruit otoliths were analyzed for the elemental composition of the core using a Finnigan MAT Element sector field inductively coupled plasma mass spectrometer (ICP-MS) and a VG-UV microprobe Nd:YAG $266 \mathrm{~nm}$ laser ablation system (see Ruttenberg et al. 2005 for more details of the ablation system). Counts were collected for the isotopes ${ }^{24} \mathrm{Mg}$, ${ }^{48} \mathrm{Ca},{ }^{55} \mathrm{Mn},{ }^{86} \mathrm{Sr}$, and ${ }^{138} \mathrm{Ba}$. All elements were expressed as ratios relative to $\mathrm{Ca}$. The molar ratios of analyte to $\mathrm{Ca}$ were determined from the ratio of each isotope to ${ }^{48} \mathrm{Ca}$ and calibration solutions with known analyte to Ca ratios were used to calculate an isotope ratio mass bias correction (see Warner et al. 2005 for more details).

The otolith core was located on the mounted otolith in the sample cell using a 400× objective and video imaging system (see Ruttenberg et al. 2005). We define the otolith core as the otolith primordium and other material deposited during gestation, before exogenous feeding begins (Ruttenberg et al. 2005). To isolate the material associated with the core and to minimize the inclusion of non-core material, we used a series of suc- cessive small ablation pits: each ablation pit comprised 8 laser pulses $(0.1 \mathrm{~mJ}$ at $3 \mathrm{~Hz})$ in a vertical transect (see Ruttenberg et al. 2005 for details). The resulting pit was 25 to $30 \mu \mathrm{m}$ in diameter, i.e. the approximate diameter of pre-hatch larval otoliths of Sebastes atrovirens (Warner et al. 2005). This method accurately samples the core from non-core material in the otoliths of recruit $S$. atrovirens (Standish et al. 2008). Relatively elevated levels of Mn have been measured at otolith cores (Brophy et al. 2004, Macdonald et al. 2008), and this feature is an accurate indicator of the location of the natal core of the otolith for $S$. atrovirens recruits (Ruttenberg et al. 2005). We used elevated levels of Mn (at least $3 \times$ higher than surrounding material) as a proxy to identify the specific pit containing the core material in the vertical transect. Elements associated with the identified pit were used to characterize the core elemental composition. All elements analyzed ( $\mathrm{Mg}, \mathrm{Ca}, \mathrm{Mn}, \mathrm{Sr}, \mathrm{Ba})$ at the otolith core were acquired using medium resolution $(\mathrm{R}=3000)$, since $\mathrm{Mn}$ is only detectable in medium resolution.

Limits of detection for each of the elements, calculated as $3 \times$ the $\mathrm{SD}$ of a $1 \% \mathrm{HNO}_{3}$ blank sample analyzed after every otolith, were: $0.05 \mathrm{mmol} \mathrm{mol}^{-1}(\mathrm{Mg})$, $3.14 \mu \mathrm{mol} \mathrm{mol} \mathrm{m}^{-1}(\mathrm{Mn}), 0.04 \mathrm{mmol} \mathrm{mol} \mathrm{m}^{-1}(\mathrm{Sr})$, and $0.88 \mu \mathrm{mol} \mathrm{mol} \mathrm{m}^{-1}(\mathrm{Ba})$. Mean estimates of precision (\%RSD, relative standard deviation), based on replicate measurements of a solid glass standard reference material (NIST 612), were: 18.0\% (Mg), 13.8\% (Mn), $23.1 \%(\mathrm{Sr})$, and $14.8 \%(\mathrm{Ba})$. These RSD values reflect similar instrument precisions previously reported using this method (Ruttenberg et al. 2005, Warner et al. 2009). To determine whether the precision estimates for the elemental signatures could alter the conclusions of our analysis, we generated 10 simulated datasets in which the elemental signatures in the original dataset were varied by adding random numbers drawn from normal distributions with means of 0 and SDs corresponding to the RSD for each element. We then subjected each randomly varied dataset to the same Markov chain-Monte Carlo (MCMC) analysis described below. The randomly varied datasets had a mean of $71 \%$ and $74 \%$ agreement (this includes several cases in which MCMC failed to identify more than 1 cluster) with the natal signature assignments in the analysis of the original dataset (for 2001 and 2002, respectively) and exhibited similar spatial patterns, suggesting that the analytical precision did not greatly affect the conclusions drawn here.

Statistical analyses. Birthdates were calculated for 33 of the 37 otoliths chemically analyzed in 2001 and for 153 of the 173 chemically analyzed in 2002 (Table 1). We tested for significant differences among locations for date of parturition in each year using 1-way analysis of variance (ANOVA). 
Samples in which we did not detect an elevated level of $\mathrm{Mn}$ indicative of natal core, or had concentrations of $\mathrm{Mg}, \mathrm{Sr}$, or Ba below detection limits, were excluded from the analysis (5 of 42 otoliths in 2001, and 60 of 233 in 2002 , i.e. 12 to $26 \%$ ). Since elevated $\mathrm{Mn}$ in the core is likely influenced by non-environmental inputs (e.g. maternal or physiological; see Brophy et al. 2004, Ruttenberg et al. 2005), we excluded Mn from subsequent analysis after using it as a proxy to define the core location. Levels of $\mathrm{Mg}, \mathrm{Sr}$, and $\mathrm{Ba}$ at the natal core were used in the following analyses.

Recruit 'natal signature types' for each year were determined using an MCMC classification algorithm (Munch \& Clarke 2008, White et al. 2008). Given a particular number of natal signature types, this Bayesian analytical technique simultaneously estimates the parameters corresponding to each type (i.e. means and covariances of natal signatures) and assigns individuals in the samples to each type. When coupled with a model selection procedure, this approach can also estimate the number of natal signature types post hoc (White et al. 2008). Thus with limited prior information, the technique estimates the number of types and assigns individuals to them. This technique generally matches or exceeds alternative approaches such as hierarchical or $k$-means clustering because it allows greater flexibility in the covariance structure of the data (White et al. 2008).

We implemented the MCMC algorithm in Matlab 7.10 (Mathworks) following the procedures outlined by White et al. (2008). Briefly, elemental data were log transformed, and the probability of membership in a cluster was assumed to follow a multivariate normal distribution. Cluster means were also simulated from a multivariate normal distribution. Cluster covariance matrices were simulated by generating random draws for each univariate SD from an inversegamma distribution, simulating a correlation matrix from a hyperbolic-tangent-transformed normal distribution, then combining the vectors of standard deviation $\mathbf{S}$ and the correlation matrix $\mathbf{R}$ into a covariance matrix $\mathbf{C}=\operatorname{diag}(\mathbf{S}) \mathbf{R} \operatorname{diag}(\mathbf{S})$, where $\operatorname{diag}(\mathbf{V})$ is a matrix with elements of the vector $\mathbf{V}$ along the diagonal and zeros elsewhere. The mixture probabilities (the proportion of the sample drawn from each cluster) were simulated using a Metropolis-Hastings estimator coupled to the main Gibbs sampler, as described by White et al. (2008). After initial runs to examine convergence, all MCMC runs were made with 5000 iterations, a burn-in of 2000, and a thinning interval of 1 , and a post hoc relabeling algorithm was applied to correct the label-switching problem (Stephens 2000, White et al. 2008). We considered an individual otolith to be assigned to a particular cluster if its probability of membership in that cluster was $\geq 0.5$.
This analysis was performed separately for otoliths from 2001 and 2002.

In order to identify $\kappa$, the number of clusters (i.e. natal signature types) present in a dataset, we made MCMC runs with values of $K$ (the proposed number of clusters) ranging from 1 to 4 , then used the deviance information criterion (DIC) to choose the value of $K$ that afforded the most parsimonious description of the data (we used the $\mathrm{DIC}_{3}$ variant proposed by Celeux et al. 2006). Five MCMC runs were made for each value of $K$ in case any one run failed to converge on the correct solution. However, as noted by White et al. (2008), runs with large values of $K$ often converge on a solution with fewer than $K$ clusters (i.e. some of the available clusters do not have any individuals assigned to them with probability $\geq 0.5$ ). In this dataset, no MCMC run produced more than 2 occupied clusters. However, runs with values of $K$ greater than the actual number of occupied clusters often have a higher likelihood, apparently because the additional 'empty' clusters improve mixing in the Markov chain (White et al. 2008). Therefore we re-ordered the runs based on the number of occupied clusters (referred to as $K^{\prime}$ hereafter), then calculated the mean value of $\mathrm{DIC}_{3}$ across all the runs with each value of $K^{\prime}$. The value of $K^{\prime}$ with the lowest mean $\mathrm{DIC}_{3}$ was taken to be the correct number of clusters. We then chose the run with the correct number of occupied clusters and the highest likelihood to determine the assignment of individuals to each cluster.

After identifying the number of clusters, $K^{\prime}$, and the assignment of individuals to each cluster for each year, we performed several additional analyses to investigate the nature of the 'natal types' corresponding to each MCMC cluster. There is no formal means for assessing the contribution of different elements in the MCMC process. However, examining the elemental concentrations for each natal type should reveal the primary variables contributing to the identification of distinct types. Therefore, we used multivariate analysis of variance (MANOVA) to test for an effect of natal type assignment, year, and their interaction on otolith elemental signatures, followed by univariate ANOVAs with the same model terms to determine which elements contributed to the MANOVA results. MANOVA and ANOVAs were performed on log-transformed data and implemented in R 2.11.1 (R Development Core Team 2010). Additionally, in order to visualize the multivariate differences between natal types, we performed a principal components analysis (PCA) on the entire dataset (both years pooled together), and labeled the data points according to year and natal type. This analysis afforded a graphical assessment of the degree to which the elemental signatures associated with each natal type were similar across the 2 


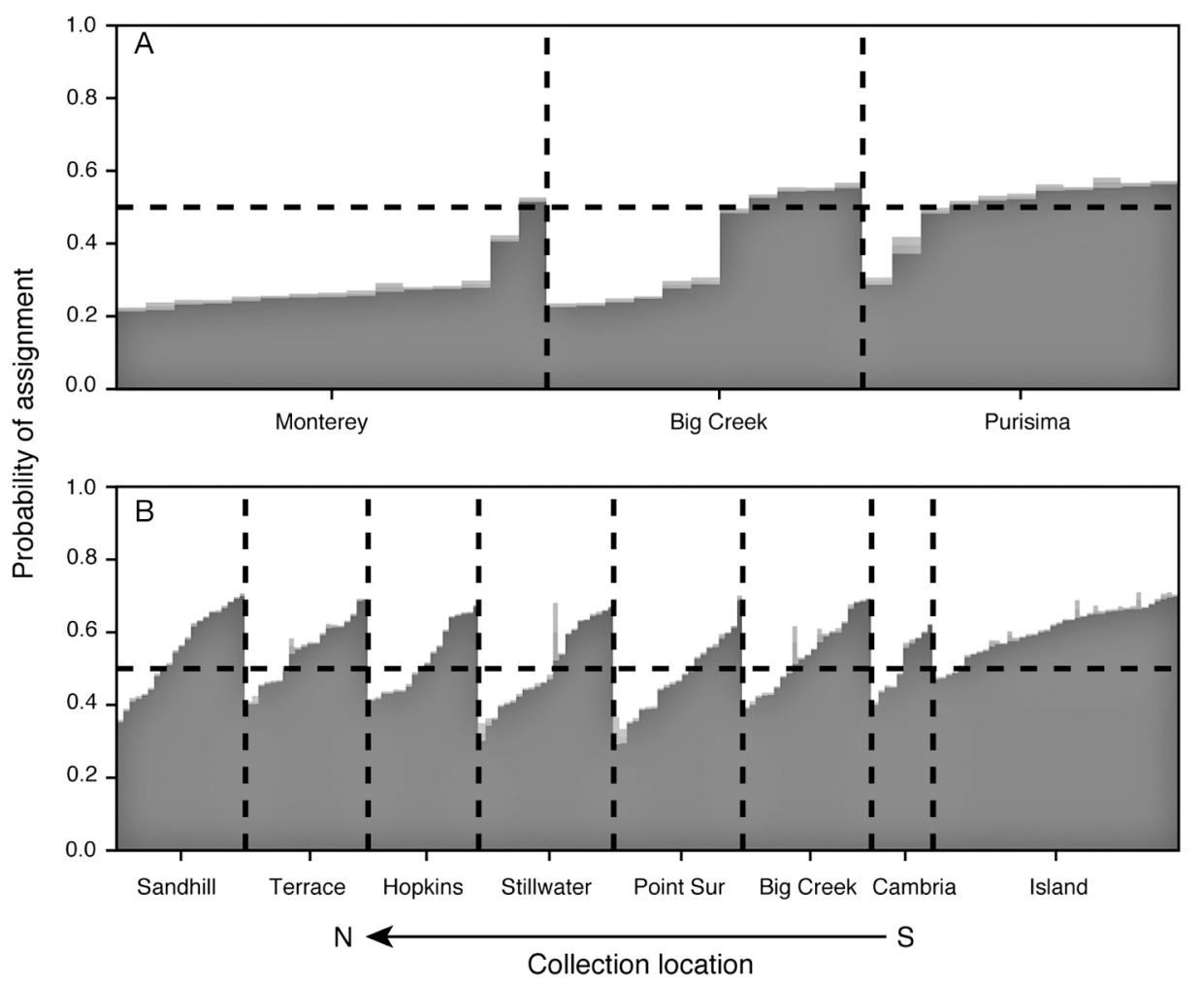

Fig. 2. Sebastes atrovirens. Probability of assignment of individual otoliths to each natal signature type in (A) 2001 and (B) 2002 using the Markov chain-Monte Carlo algorithm. Each vertical bar corresponds to 1 sampled individual. The shading corresponds to the probability of assignment to natal signature Type A (dark gray), Type B (white), or Type C or D (light gray shades). Probabilities sum to 1 . Individuals are grouped by sampling site along the horizontal axis (set off by vertical dashed lines). Horizontal dashed line indicates $50 \%$ threshold for assignment to a group. The assignments were produced by the best model runs identified by the model-selection procedure

years. The PCA was performed in Matlab 7.10 on unstandardized, logtransformed data.

\section{RESULTS}

\section{Otolith microstructure}

Each location included fish of a range of ages and birthdates (Table 1). The distribution of recruit birthdates from the collection locations within years overlaid each other. There was no significant difference in the average birthdate of recruits among locations in 2001 (ANOVA, 2001: $F_{2,30}=$ 0.30, $p=0.74$ ). In 2002, the average birthdate of recruits was significantly different among locations $\left(F_{7,145}=\right.$ 35.86, $\mathrm{p}<0.0001)$ due to younger
Table 2. Summary of model selection to determine the number of clusters in the recruit core dataset in 2001 and 2002. Markov chain-Monte Carlo (MCMC) runs were grouped by (a) the number of possible clusters in the run $(K)$, and (b) the number of occupied clusters after convergence $\left(K^{\prime}\right)$. While values of $K$ from 1 to 4 were tried, no runs converged on a value of $K^{\prime}$ greater than 2. Mean log-likelihood is the log-likelihood of the data given all parameters, averaged across all MCMC runs with that value of $K^{\prime} ; \mathrm{DIC}_{3}$ is a variant of the deviance information criterion proposed by Celeux et al. (2006); $\mathrm{n}$ is the number of MCMC runs with that value of $K$ or $K^{\prime}$. Runs that did not converge were excluded from this summary

\begin{tabular}{|c|c|c|c|c|}
\hline & \multicolumn{2}{|c|}{ Mean log-likelihood \pm SD (n) } & \multicolumn{2}{|c|}{ Mean $\mathrm{DIC}_{3} \pm \mathrm{SD}(\mathrm{n})$} \\
\hline & 2001 & 2002 & 2001 & 2002 \\
\hline \multicolumn{5}{|c|}{ (a) $K$} \\
\hline 1 & $-91.1 \pm 0.0(5)$ & $-415.8 \pm 0.0(5)$ & $242.3 \pm 0.1(5)$ & $1173.4 \pm 93.2(5)$ \\
\hline 2 & $-89.2 \pm 1.4(5)$ & $-367.3 \pm 2.2(4)$ & $250.4 \pm 5.0(5)$ & $1016.8 \pm 2.7(4)$ \\
\hline 3 & $-91.0 \pm 6.8(5)$ & $-360.7 \pm 0.7(5)$ & $243.3 \pm 5.5(5)$ & $990.4 \pm 2.8(5)$ \\
\hline 4 & $-88.0 \pm 2.0(3)$ & $-355.0 \pm 0.0(5)$ & $254.4 \pm 32.7$ (3) & $968.3 \pm 0.4(5)$ \\
\hline \multicolumn{5}{|c|}{ (b) $K^{\prime}$} \\
\hline 1 & $-90.3 \pm 3.6(18)$ & $-406.0 \pm 34.8(6)$ & $247.2 \pm 12.8(18)$ & $1141.7 \pm 113.4(6)$ \\
\hline 2 & $-86.9 \pm 0.0(1)$ & $-360.8 \pm 5.9(13)$ & $235.4 \pm 0.0(1)$ & $990.6 \pm 22.2(13)$ \\
\hline 3 & - & - & - & - \\
\hline 4 & - & - & - & - \\
\hline
\end{tabular}


birthdates of recruits at Santa Cruz Island relative to the mainland samples (Table 1).

\section{Otolith microchemistry}

In both 2001 and 2002, $\mathrm{DIC}_{3}$ was lowest for $K^{\prime}=2$ (Table 2), suggesting that the sample of recruit otoliths consisted of 2 distinct natal signature types (Types 'A' and ' $\mathrm{B}$ ') in each year.

To examine the pattern of assignments to each natal type within each year, we focused on the assignment probabilities produced by the MCMC run with the highest mean likelihood (of those that had $K^{\prime}=2$ ). In both years, this MCMC run had $K=4$, so while there were only 2 occupied clusters (natal types), and each individual had a $>50 \%$ probability of assignment to 1 of those 2 clusters, many also had small but non-0 probabilities of assignment to a third and fourth type (this is a common feature of assignments using this type of algorithm; White et al. 2008). However, no individual had $>3 \%$ (in 2001) or $>9 \%$ (in 2002) probability of assignment to the third or fourth type. In 2001, most recruit cores assigned to Type B had $>70 \%$ assignment probability to that type, while the probability of assignment to Type A rarely exceeded $60 \%$ (Fig. 2a). Assignment probabilities indicate the level of confidence in the assignment; although some of these assignments were near $50 \%$, there did appear to be 2 distinct natal signature types. Assignment probabilities were generally higher in the 2002 dataset; most individuals were assigned to either Type A or B with $>60 \%$ probability (Fig. 2b)

To determine whether the 2 natal signature types in the 2 yr represented similar multivariate elemental signatures, we performed a PCA on the combined dataset (both 2001 and 2002 recruit cores). We plotted the data along the first 2 principal axes, and then examined the spatial overlap of recruit cores assigned to each signature type in each year (Fig. 3). Data from the 2 yr overlapped completely in principal component space, indicating that natal signatures were chemically similar in the 2 yr. Furthermore, the multivariate separation between the 2 natal signature types was similar in both years. That is, in each year there were 2 distinct natal signature types, and these 2 natal signatures types were similar and mostly distinct across both years. Therefore, we refer to these signature types as Type A and $B$ hereafter (the 2 unoccupied clusters mentioned above would be Types $\mathrm{C}$ and $\mathrm{D}$ ). The only overlap in multivariate space between the 2 types is visible just to the right of the center of Fig. 3, where some Type B individuals from 2001 coincide with Type A individuals from 2002. The principal component loadings indicated that the difference between the 2 natal types,

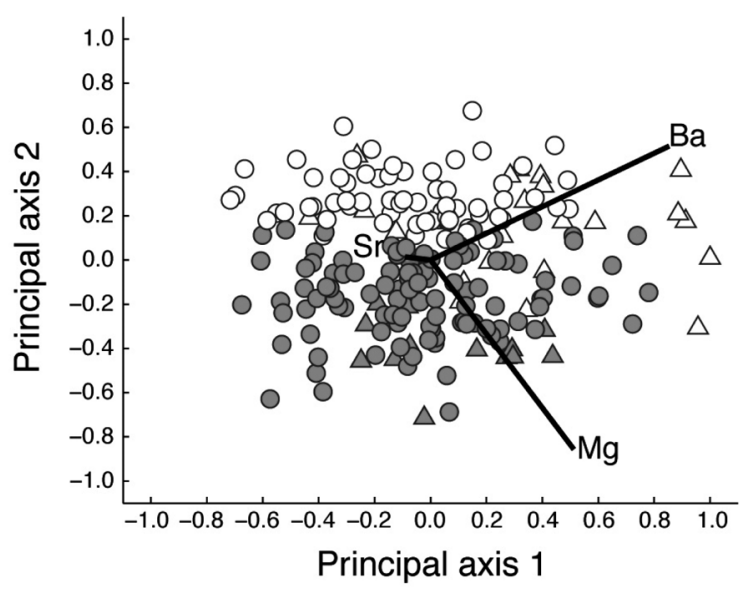

Fig. 3. Sebastes atrovirens. Principal components ordination of elemental signatures in recruit otolith cores. Data from both 2001 and 2002 were pooled for calculation of principal components. Marker shape indicates sample year ( $\Delta: 2001$; O: 2002); shade indicates assignment to natal signature type by Markov chain-Monte Carlo analysis (gray: Type $A_{\text {; }}$ white: Type B). Assignment to natal signature type was calculated independently for each sample year. Principal component scores were scaled to a maximum value of 1 . Black lines indicate principal axis loadings of the 3 elemental concentrations

which is associated primarily with the second principal component axis, was primarily due to differences in $\mathrm{Mg}$ and Ba concentrations (Fig. 3).

We used MANOVA to further test for differences in elemental signatures among the natal types. This test revealed a significant effect of natal type, year, and a year $\times$ type interaction (Table 3a). We then performed univariate ANOVA tests of the same null hypothesis, which revealed that in both years, natal signature Type A had significantly higher Mg and lower Ba concentrations than Type B, but that Sr concentrations were not significantly different between the 2 types (Table 3b, Fig. 4). There were also differences in mean concentrations of all 3 elements between the 2 years, and Type B had a much higher mean Ba concentration in 2001 than in 2002 (significant natal type $\times$ year effect; Table 3b, Fig. 4). Overall these results suggest that the MCMC procedure identified 2 clusters based primarily on differences in $\mathrm{Ba}$ and $\mathrm{Mg}$ concentrations.

In both 2001 and 2002, the pattern of assignment to natal signature type varied among sites. In the 2001 recruitment season, Type A increased in frequency southward along the coast from Monterey to Purisima, and was rare at the northern location, while Type B had the opposite pattern. Only 1 individual was characterized as natal Type A at Monterey in 2001 (Figs. 1 \& 2a). In contrast, natal signature types were more evenly distributed among locations in 2002. Both Types $\mathrm{A}$ and $\mathrm{B}$ were present in recruit collections at all loca- 
Table 3. Sebastes atrovirens. Multivariate and univariate ANOVAs to detect differences in elemental signatures among natal types identified by Markov chain-Monte Carlo (MCMC) analysis and between years 2001 and 2002. (a) MANOVA with all 3 elemental concentrations as the response; (b) univariate ANOVAs on each element. * values that are significantly different from 0 at level of at least $\alpha=0.05$. Analyses were performed on log-transformed data

\begin{tabular}{|c|c|c|c|c|}
\hline $\begin{array}{l}\text { (a) MANOVA } \\
\text { Source }\end{array}$ & Wilk's $\lambda$ & $\mathrm{df}$ & $F$ & $\mathrm{p}$ \\
\hline Natal type & 0.369 & 3,201 & 114.459 & $<1 \times 10^{-8 *}$ \\
\hline Year & 0.788 & 3,201 & 18.040 & $<1 \times 10^{-8 *}$ \\
\hline Natal type $\times$ Year & 0.953 & 3,201 & 3.277 & $2.21 \times 10^{-2 *}$ \\
\hline (b) ANOVA & $\mathrm{df}$ & SS & $F$ & $\mathrm{p}$ \\
\hline \multicolumn{5}{|l|}{ Response: Mg } \\
\hline Natal type & 1 & 37.858 & 122.628 & $<1 \times 10^{-8 *}$ \\
\hline Year & 1 & 16.328 & 52.889 & $<1 \times 10^{-8 *}$ \\
\hline Natal type $\times$ Year & 1 & 0.232 & 0.751 & 0.387 \\
\hline Error & 203 & 62.671 & & \\
\hline \multicolumn{5}{|l|}{ Response: $\mathrm{Sr}$} \\
\hline Natal type & 1 & 0.007 & 0.172 & 0.679 \\
\hline Year & 1 & 0.214 & 5.083 & $0.025^{*}$ \\
\hline Natal type $\times$ Year & 1 & 0.007 & 0.160 & 0.689 \\
\hline Error & 203 & 8.559 & & \\
\hline \multicolumn{5}{|l|}{ Response: Ba } \\
\hline Natal type & 1 & 22.372 & 40.706 & $<1 \times 10^{-8 *}$ \\
\hline Year & 1 & 4.722 & 8.591 & $3.76 \times 10^{-3 *}$ \\
\hline Natal type $\times$ Year & 1 & 4.876 & 8.872 & $3.25 \times 10^{-3 *}$ \\
\hline Error & 203 & 111.569 & & \\
\hline
\end{tabular}

tions from northern Monterey to the Channel Islands (Figs. 1 \& 2b). In general, Type A was most common in the extreme southern and northern parts of the spatial domain, with higher frequencies at Sand Hill, Terrace Point, Cambria, and Santa Cruz Island (Figs. 1 \& 2b). The lowest frequency of Type A recruits was at Point Sur, near the center of the array of collection sites, and other sites in the central part of the spatial domain also had lower-than-average proportions of Type A (Monastery and Cambria).

Despite some differences in the spatial pattern of natal types between the 2 recruitment seasons, regional oceanographic conditions were similar for both years. The California current system was characterized by similar circulation patterns and oceanographic features along the coast during the spring and summer of 2001 and 2002 (Durazo et al. 2001, Schwing et al. 2002).

\section{DISCUSSION}

Recent work using otolith chemistry demonstrated geographically distinct natal elemental signatures in the larval otoliths of species that spawn along the open
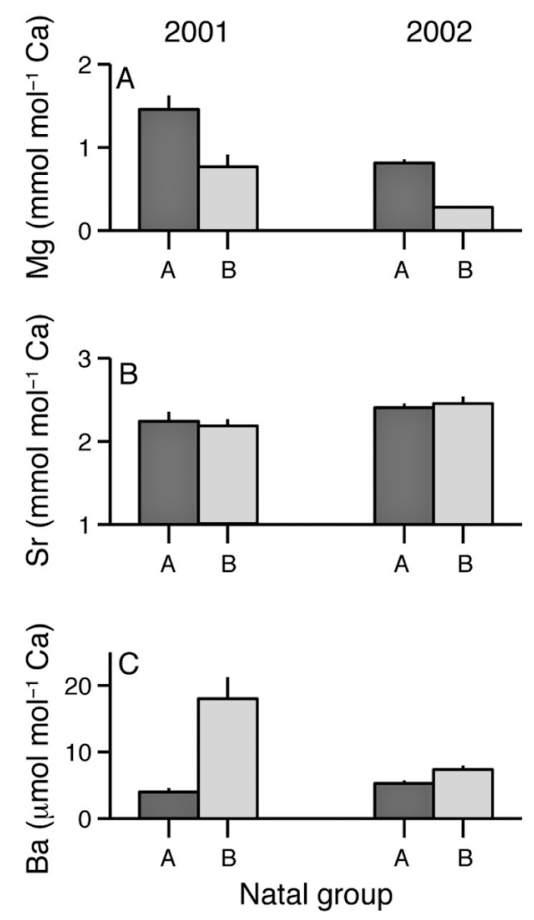

Fig. 4. Sebastes atrovirens. Elemental concentrations (mean $+1 \mathrm{SE}$ ) in recruit otolith cores collected in 2001 (left bars) and 2002 (right bars) grouped by natal type as identified by Markov chain-Monte Carlo analysis. Concentrations are expressed relative to $\mathrm{Ca}$

coast at spatial scales of $10 \mathrm{~s}$ to $100 \mathrm{~s}$ of kilometers (Warner et al. 2005, Ruttenberg \& Warner 2006). The unique source signatures are retained within the otolith and can be analyzed by discretely isolating and measuring the core (natal portion) of the otolith of postsettled individuals (Ruttenberg et al. 2005). In the present study, we found sufficient variation in the elemental concentrations at the otolith cores of recently recruited kelp rockfish collected from locations along the coast of California, resulting in unique elemental signature types. The classification model identified 2 distinct natal signature types among sampled individuals in 2001 and 2002. These results suggest that natal elemental signatures from sources along the coast varied sufficiently at this large geographic scale (10s to $100 \mathrm{~s} \mathrm{~km}$ ) in 2 separate years to produce distinct elemental signature types in the otolith cores of recently recruited individuals.

Studies analyzing the variation in elemental signatures at the early larval and juvenile portions of the otoliths of young fish have found significant differences among locations that imply separate origins and dispersal trajectories during the early larval and pelagic juvenile period (Miller \& Shanks 2004, Ashford et al. 2006). For this study, we were most interested in differences of natal types between locations, such as 
the restriction of a natal type(s) to a particular region along the coast, to evaluate potential barriers to dispersal. In the 2001 recruitment season, there were strong differences in the presence of specific natal types observed at Monterey, Big Creek, and Purisima, suggesting differences in the contribution of chemically distinct natal sources to the juvenile cohort at each location (Fig. 1). There was a strong spatial gradient in natal types with near exclusion of Type A from Monterey, implying restricted dispersal at this scale and limited contribution of the distinct natal signature type to the north. Larval dispersal patterns are likely a result of many factors, including ocean currents and larval behavior. Possible barriers to dispersal, such as recirculating oceanographic currents and mesoscale eddies, are common along the coast of California and entrain planktonic larvae, limiting alongshore transport (e.g. Wing et al. 1998, Diehl et al. 2007). Such features may have contributed to the spatial pattern of natal types we observed. In addition, larval behavior may retard passive dispersal within currents and assist in retaining individuals nearshore (Largier 2003, Shanks 2009). The approach taken here of analyzing the spatial pattern of natal elemental signatures in the otoliths of recently settled individuals provides a useful method to quantify the degree to which natal signature types are not mixed among locations, and thus to examine larval dispersal patterns over a large geographic area.

The restriction of a natal signature type to a particular location along the coast can suggest the existence of barriers to larval dispersal (such as the rarity of 'southern' signature Type A at Monterey in 2001). However, the converse is not necessarily true; similarities in natal signature types of recruits at different locations do not provide conclusive information regarding dispersal patterns. This is because recruits with the same natal type could have either originated from the same source location or originated from multiple source populations with the same distinctive elemental signature. Unlike 2001, both natal signature types were present and relatively abundant at all locations sampled in 2002 (Fig. 1). While this result implies considerable larval movement among source populations along the coast in 2002, the geographic identity of the contributing source(s) with the natal signature types is not known. Therefore, caution should be used in interpreting the interannual differences in the spatial pattern of natal types as evidence for interannual differences in connectivity. Although we believe that interannual variability in the degree of larval mixing is the most parsimonious interpretation of these data, we cannot rule out the possibility that only the spatial distribution of elemental signatures shifted, and the spatial pattern of larval dispersal was actually similar in 2001 and 2002.
Along the open coast, gradients in temperature and trace element inputs exist that may affect otolith elemental composition, especially in locations characterized by distinctive hydrographic processes. For instance, areas of coastal upwelling transport cold, nutrient-rich waters to the surface and are characterized by trace element (e.g. Ba) enrichment relative to waters in non-upwelled regions (Bruland 1983). Extensive research on fish otoliths has sometimes shown linear relationships between the concentrations of elements in seawater (e.g. $\mathrm{Ba}, \mathrm{Sr}$ ) and in the chemical composition of the otolith (Bath et al. 2000, Elsdon \& Gillanders 2003). In the current study, natal Types A and $B$ were characterized by significant differences in $\mathrm{Ba}$ and $\mathrm{Mg}$ concentrations. Interestingly, natal Type B, characterized by significantly elevated Ba concentration, was observed at higher frequencies in both years along the central coast where upwelling is predominant. In contrast, natal Type A was most prevalent at the extreme southern location in 2001 and 2002 and was characterized by relatively low Ba concentrations. This may point to potential sources for the natal types, such as regions bathed in upwelled waters along the central and northern coastlines (Type B) and coastlines influenced by the non-upwelled waters (Type A). However, we still lack sufficient information regarding the mechanisms controlling the incorporation of elements into the otolith during the embryonic phase to be able to relate particular natal type elemental signatures to specific environmental conditions and/or geographic source (Warner et al. 2005).

The incorporation of elements at the core of the otolith is likely a combination of multiple factors including environmental influences, developmental (e.g. variation in Ca-binding proteins in the endolymph; Kalish 1989, de Pontual et al. 2003), physical factors (e.g. changes in otolith crystal structure; Brown \& Severin 1999), and maternal contributions (Ruttenberg et al. 2005, Thorrold et al. 2006). Warner et al. (2005) found strong maternal effects for all elements analyzed (significant between-brood, within-region differences) in addition to distinct regional differences in natal elemental signatures in the otoliths of prerelease Sebastes atrovirens in southern California. The distinct oceanographic features along the coast that affect water chemistry and temperature along with consistent spatial differences in maternal contributions (e.g. mothers in the same region, with similar diets, likely show geographical patterns of maternal effects) likely contributed to the existence of the chemically distinct natal types we observed in 2001 and 2002. Nonetheless, this pattern does not preclude the possibility that the differences in natal types may reflect differing physiological abilities among individuals to regulate elemental concentrations at the core that may or 
may not be related to geography (Kalish 1991). Our findings support further investigation into otolith chemistry in the natal core of juvenile otoliths and into the mechanisms generating the otolith natal signatures themselves.

One alternative approach to sampling the natal elemental signatures in otoliths that precludes maternal influences is the exclusion of material associated with the core ablation pit from analysis. Macdonald et al. (2008) analyzed the otolith elemental signatures of age- 0 and age- 1 Australian smelt Retropinna semoni at a target region of the otolith that included material accreted onto the otolith 2 to $10 \mathrm{~d}$ post hatch to characterize the natal chemical signature. By excluding otolith material representing the primordium (e.g. identified by the Mn peak), they found improved discriminatory power when assigning known-origin individuals to their natal site. However, there are limitations with this type of approach in identifying natal signatures. For instance, it is necessary that post-hatch or post-release larvae remain at the natal location for a substantial amount of time ( $\sim 7$ to $10 \mathrm{~d}$, depending on the quality of the laser and the ablation spot size). For the majority of open coast species, little is known about the length of time larvae spend at the natal location once spawned or released. If larvae move offshore days after release or hatching to environments where the chemical and physical properties differ from the natal source, this would confound the characterization of the natal elemental signature.

In summary, this study demonstrates the use of natal elemental signatures in the otolith cores of recruits to examine larval dispersal patterns along open coastlines and the degree to which different populations receive recruits from different sources. Natal elemental signatures in the otolith cores of recruits varied sufficiently to produce distinct elemental signature types, indicating the contribution of chemically distinct sources. The spatial pattern of natal elemental types revealed that locations along the coast received a mixture of natal types during both recruitment seasons, suggesting that at least 2 distinct sources contributed to recruitment at each site. Moreover, we found strong differences among sites in the occurrence of specific natal types, suggesting limited larval dispersal along this region of the California coastline. Although more information regarding the mechanisms controlling the incorporation of elements at the natal portion of the otolith is needed to be able to relate natal type elemental signatures to specific seawater properties and geographic source, our results indicate that further analysis of elemental signatures in the otolith cores of fish may yield important information about larval dispersal in open-coast environments.
Acknowledgements. This work was supported by the Partnership for Interdisciplinary Studies of Coastal Oceans (PISCO), funded jointly by the David and Lucile Packard Foundation and the Gordon and Betty Moore Foundation. Financial support was also provided by the Coastal Environmental Quality Initiative (CEQI, funded by the University of California Marine Council), and Environmental Defense. We are grateful to M. Burford, M. Sheehy, D. Johnson, and J. Figurski for assistance with field collections. We thank A. Haupt and R.J. Barr for help with otolith preparation and G. Paradis for technical assistance. This manuscript benefitted greatly from the comments of 3 anonymous reviewers. This is PISCO Contribution no. 391.

\section{LITERATURE CITED}

Almany GR, Berumen ML, Thorrold SR, Planes S, Jones GP (2007) Local replenishment of coral reef fish populations in a marine reserve. Science 316:742-744

Ammann AJ (2004) SMURFs: standard monitoring units for the recruitment of temperate reef fishes. J Exp Mar Biol Ecol 299:135-154

Ashford JR, Arkhipkin AI, Jones CM (2006) Can the chemistry of otolith nuclei determine population structure of Patagonian toothfish Dissostichus eleginoides? J Fish Biol 69:708-721

Bath GE, Thorrold SR, Jones CM, Campana SE, McLaren JW, Lam JWH (2000) Strontium and barium uptake in aragonitic otoliths of marine fish. Geochim Cosmochim Acta 64: 1705-1714

Becker BJ, Levin LA, Fodrie FJ, McMillan PA (2007) Complex larval connectivity patterns among marine invertebrate populations. Proc Natl Acad Sci USA 104:3267-3272

Botsford LW, Micheli F, Hastings A (2003) Principles for the design of marine reserves. Ecol Appl 13:25-31

Botsford LW, White JW, Coffroth MA, Paris C and others (2009) Connectivity and resilience of coral reef metapopulations in MPAs: matching empirical efforts to predictive needs. Coral Reefs 28:327-337

Broitman BR, Blanchette CA, Menge BA, Lubchenco J and others (2008) Spatial and temporal patterns of invertebrate recruitment along the west coast of the United States. Ecol Monogr 78:403-421

- Brophy D, Jeffries TE, Danilowicz BS (2004) Elevated manganese concentrations at the cores of clupeid otoliths: possible environmental, physiological, or structural origins. Mar Biol 144:779-786

Brown R, Severin KP (1999) Elemental distribution within polymorphic inconnu (Stenodus leucichthys) otoliths is affected by crystal structure. Can J Fish Aquat Sci 56: 1898-1903

Bruland KW (1983) Trace elements in seawater. In: Riley JP, Chester R (eds) Chemical oceanography. Vol. 8. Academic Press, London, p 157-220

Buonaccorsi VP, Westerman M, Stannard J, Kimbrell C, Lynn E, Vetter RD (2004) Molecular genetic structure suggests limited larval dispersal in grass rockfish, Sebastes rastrelliger. Mar Biol 145:779-788

Burford MO, Larson RJ (2007) Genetic heterogeneity in a single year-class from a panmictic population of adult blue rockfish (Sebastes mystinus). Mar Biol 151:451-465

Caley MJ, Carr MH, Hixon MA, Hughes TP, Jones GP, Menge BA (1996) Recruitment and the local dynamics of open marine populations. Annu Rev Ecol Syst 27:477-500

> Campana SE (1999) Chemistry and composition of fish otoliths: pathways, mechanisms and applications. Mar 
Ecol Prog Ser 188:263-297

Campana SE, Fowler AJ, Jones CM (1994) Otolith elemental fingerprinting for stock identification of Atlantic cod (Gadus morhua) using laser-ablation ICPMS. Can J Fish Aquat Sci 51:1942-1950

Carr MH, Reed DC (1993) Conceptual issues relevant to marine harvest refuges: examples from temperate reef fishes. Can J Fish Aquat Sci 50:2019-2028

Celeux GF, Forbes F, Robert CP, Titterington DM (2006) Deviance information criteria for missing data models. Bayesian Anal 1:651-674

de Pontual H, Lagarde`re F, Amara R, Bohn M, Ogor A (2003) Influence of ontogenetic and environmental changes in the otolith microchemistry of juvenile sole (Solea solea). J Sea Res 50:199-210

> de Vries MC, Gillanders BM, Elsdon TS (2005) Facilitation of barium uptake into fish otoliths: influence of strontium concentration and salinity. Geochim Cosmochim Acta 69: 4061-4072

DiBacco C, Levin LA (2000) Development and application of elemental fingerprinting to track the dispersal of marine invertebrate larvae. Limnol Oceanogr 45:871-880

> Diehl JM, Toonen RJ, Botsford LW (2007) Spatial variability of recruitment in the sand crab Emeritia analoga throughout California in relation to wind-driven currents. Mar Ecol Prog Ser 350:1-17

Durazo R, Collins CA, Hyrenbach KD, Schwing FB and others (2001) The state of the California current, 2000-2001: a third straight La Niña year. Calif Coop Ocean Fish Invest Rep 42:29-60

Elsdon TS, Gillanders BM (2003) Relationship between water and otolith elemental concentrations in juvenile black bream Acanthopagrus butcheri. Mar Ecol Prog Ser 260: $263-272$

Fontes J, Caselle JE, Sheehy MS, Santos RS, Warner RR (2009) Natal signatures of juvenile Coris julis in the Azores: investigating connectivity scenarios in an oceanic archipelago. Mar Ecol Prog Ser 387:51-59

Fowler AJ, Gillanders BM, Hall KC (2005) Relationship between elemental concentration and age from otoliths of adult snapper (Pagrus auratus, Sparidae): implications for movement and stock structure. Mar Freshw Res 56: 661-676

Gillanders BM (2002) Connectivity between juvenile and adult fish populations: do adults remain near their recruitment estuaries? Mar Ecol Prog Ser 240:215-223

Hamilton SL, Regetz J, Warner RR (2008) Postsettlement survival linked to larval life in a marine fish. Proc Nat Acad Sci USA 105:1561-1566

> Harms S, Winant CD (1998) Characteristic patterns of the circulation in the Santa Barbara Channel. J Geophys Res 103:3041-3065

Horn MH, Allen LG, Lea RN (2006) Biogeography. In: Allen LG, Pondella DJ, Horn MH (eds) The ecology of marine fishes: California and adjacent waters. University of California Press, Berkeley, CA, p 3-25

> Hyde JR, Vetter RD (2009) Population genetic structure in the redefined vermilion rockfish (Sebastes miniatus) indicates limited larval dispersal and reveals natural management units. Can J Fish Aquat Sci 66:1569-1581

Jones GP, Milicich MJ, Emslie MJ, Lunow C (1999) Selfrecruitment in a coral reef fish population. Nature 402: 802-804

> Kalish JM (1989) Otolith microchemistry: validation of the effects of physiology, age, and environment on otolith composition. J Exp Mar Biol Ecol 132:151-178

Kalish JM (1991) Determinants of otolith chemistry: seasonal variation in the composition of blood plasma, endolymph and otoliths of bearded rock cod Pseudophycis barbatus. Mar Ecol Prog Ser 74:137-159

Kinlan BP, Gaines SD (2003) Propagule dispersal in marine and terrestrial environments: a community perspective. Ecology 84:2007-2020

> Largier JL (2003) Considerations in estimating larval dispersal distances from oceanographic data. Ecol Appl 13:71-89

Love MS, Yoklavich MM, Thorsteinson L (2002) The rockfishes of the northeast Pacific. University of California Press, Berkeley, CA

Macdonald JI, Shelley JM, Crook DA (2008) A method for improving the estimation of natal chemical signatures in otoliths. Trans Am Fish Soc 137:1674-1682

Miller JA, Shanks AL (2004) Evidence for limited larval dispersal in black rockfish (Sebastes melanops): implications for population structure and marine-reserve design. Can J Fish Aquat Sci 61:1723-1735

Munch SB, Clarke LM (2008) A Bayesian approach to identifying mixtures from otolith chemistry data. Can J Fish Aquat Sci 65:2742-2751

> Plaza G, Katayama S, Omori M (2001) Otolith microstructure of the black rockfish, Sebastes inermis. Mar Biol 139: 797-805

R Development Core Team (2010) R: a language and environment for statistical computing. R Foundation for Statistical Computing, Vienna. Available at www.R-project.org

Ralston S, Brothers EB, Roberts DA, Sakuma KM (1996) Accuracy of age estimates for larval Sebastes jordani. Fish Bull 94:89-97

Ruttenberg BI, Warner RR (2006) Spatial variation in the chemical composition of natal otoliths from a reef fish in the Galapagos Islands. Mar Ecol Prog Ser 328:225-236

> Ruttenberg BI, Hamilton SL, Hickford MJH, Paradis GL and others (2005) Elevated levels of trace elements in cores of otoliths and their potential for use as natural tags. Mar Ecol Prog Ser 297:273-281

> Ruttenberg BI, Hamilton SL, Warner RR (2008) Spatial and temporal variation in the natal otolith chemistry of a Hawaiian reef fish: prospects for measuring population connectivity. Can J Fish Aquat Sci 65:1181-1192

Schwing FB, Castro G, Valdez J, Kosro PM and others (2002) The state of the California current, 2001-2002: Will the California system keep its cool, or is El Niño looming? Calif Coop Ocean Fish Invest Rep 43:31-68

- Secor DH, Rooker JR, Zlokovitz E, Zdanowicz VS (2001) Identification of riverine, estuarine, and coastal contingents of Hudson River striped bass based upon otolith elemental fingerprints. Mar Ecol Prog Ser 211:245-253

Shanks AL (2009) Pelagic larval duration and dispersal distance revisited. Biol Bull (Woods Hole) 216:373-385

> Standish JD, Sheehy M, Warner RR (2008) The use of otolith natal element signatures as natural tags to evaluate connectivity among open-coast fish populations. Mar Ecol Prog Ser 356:259-268

> Stephens M (2000) Dealing with label switching in mixture models. J R Stat Soc Ser B Stat Method 62:795-809

Swearer SE, Caselle JE, Lea DW, Warner RR (1999) Larval retention and recruitment in an island population of a coral-reef fish. Nature 402:799-802

Thorrold SR, Latkoczy C, Swart PK, Jones CM (2001) Natal homing in a marine fish metapopulation. Science 291: $297-299$

> Thorrold SR, Jones GP, Planes S, Hare JA (2006) Transgenerational marking of embryonic otoliths in marine fishes using barium stable isotopes. Can J Fish Aquat Sci 63: 1193-1197 
Warner RR, Cowen RK (2002) Local retention of production in marine populations: Evidence, mechanisms, and consequences. Bull Mar Sci 70:245-249

Warner RR, Swearer SE, Caselle JE, Sheehy M, Paradis G (2005) Natal trace-elemental signatures in the otoliths of an open-coast fish. Limnol Oceanogr 50:1529-1542

Warner RR, Hamilton SL, Sheehy MS, Zeidberg LD, Brady BC, Caselle JE (2009) Geographic variation in natal and early larval trace-elemental signatures in the statoliths of the market squid Doryteuthis (formerly Loligo) opalescens. Mar Ecol Prog Ser 379:109-121

White JW, Standish JD, Thorrold SR, Warner RR (2008) Markov chain Monte Carlo methods for assigning larvae

Editorial responsibility: Ivan Nagelkerken,

Nijmegen, Netherlands to natal sites using natural geochemical tags. Ecol Appl 18: 1901-1913

Wing SR, Botsford LW, Ralston SV, Largier JL (1998) Meroplanktonic distribution and circulation in a coastal retention zone of the northern California upwelling system. Limnol Oceanogr 43:1710-1721

Wourms JP (1991) Reproduction and development of Sebastes in the context of the evolution of piscine viviparity. Environ Biol Fishes 30:111-126

Yoklavich MM, Boehlert GW (1987) Daily growth increments in otoliths of juvenile black rockfish, Sebastes melanops: an evaluation of autoradiography as a new method of validation. Fish Bull 85:826-832

Submitted: July 8, 2010; Accepted: June 3, 2011

Proofs received from author(s): August 29, 2011 